\title{
Increased Rat Neonatal Activity Influences Adult Cytokine Levels and Relative Muscle Mass
}

\author{
BRYCE BUCHOWICZ, TIFFANY YU, DWIGHT M. NANCE, FRANK P. ZALDIVAR, DAN M. COOPER, \\ AND GREGORY R. ADAMS
}

\author{
Departments of Physiology and Biophysics [B.B., T.Y., G.R.A.], Physical Medicine \& Rehabilitation [D.M.N.], and Pediatrics [F.P.Z., \\ D.M.C.], University of California at Irvine, Irvine, California 92697
}

\begin{abstract}
Little is known about the effect of physical activity in early life on subsequent growth and regulation of inflammation. We previously reported that exposure of muscles in growing rats to IL-6 results in decreased muscle growth apparently because of a state of resistance to growth factors such IGF-I and that running exercise could ameliorate this growth defect. Herein, we hypothesized that increased activity, for a brief period during neonatal life, would pattern the adult rat toward a less inflammatory phenotype. Neonatal rats were induced to move about their cage for brief periods from $\mathrm{d}$ 5 to d 15 postpartum. Additional groups were undisturbed controls (CONs) and handled (HAND). Subgroups of rats were sampled at the age of 30 and $65 \mathrm{~d}$. Relative to CON and HAND groups, the neonatal exercise (EX) group demonstrated a decrease in circulating levels of $\mathrm{TNF} \alpha$, IL-6, and IL- $1 \beta$ in adulthood, primarily in male rats. In addition, adult male EX rats had lower body mass and increased skeletal muscle mass suggesting a leaner phenotype. The results of this study suggest that moderate increases in activity early in life can influence the adult toward a more healthy phenotype with regard to inflammatory mediators and relative muscle mass. (Pediatr Res 68: 399-404, 2010)
\end{abstract}

$\mathrm{T}_{\mathrm{t}}^{\mathrm{b}}$ he number of children with chronic inflammatory conditions is rapidly increasing. Whether in environmentally induced conditions, such as in childhood obesity, or the result of pediatric chronic lung diseases, such as severe asthma or cystic fibrosis, chronic elevations of certain mediators (e.g. IL-6, C-reactive protein) in many childhood diseases are associated with relatively reduced lean tissue and muscle mass, reduced physical activity, and long-term impairments of health (1-5). The precise mechanisms of the impairments in muscle mass are not known. However, work from this and other laboratories shows that physical activity influences muscle growth through the balance of growth factors (e.g. growth hormone and IGF-I) and stress or inflammatory mediators (e.g. IL-6), which can inhibit the anabolic effects of growth mediators associated with the GH $\rightarrow$ IGF-I axis on skeletal muscle growth and development $(6,7)$.

Received March 29, 2010; accepted July 14, 2010.

Correspondence: Gregory R. Adams, Ph.D., Department of Physiology and Biophysics, University of California at Irvine, Medical Sciences 1, Room D335, Irvine, CA 92697; e-mail: GRAdams@uci.edu

Supported by Grant P01HD048721 from the National Institutes of Health.

B.B. and T.Y. contributed equally to this work.
Although emerging data indicate that regular exercise can ameliorate inflammation $(8,9)$, very little is known about the effect of physical activity in early life on subsequent growth and regulation of inflammation. The inverse relationship between body and muscle mass and circulating levels of inflammatory cytokines is striking and has now been observed in a wide range of human subjects from premature babies (10) to elderly adults (11). We recently reported that the direct exposure of muscles in growing rats to IL-6 results in decreased muscle growth apparently because of a state of resistance to growth factors such as IGF-I (12). The mechanistic link between proinflammatory cytokines and skeletal muscle growth factors probably lies in the activity of the SOCS (suppressors of cytokine signaling) family of proteins $(13,14)$.

A growing number of investigations are providing support for the concept of "critical periods of growth" during which relatively short-term physiological perturbations early in life can lead to long-term health consequences in adulthood, particularly with reference to body composition and obesity (15-19). Although much attention has been paid to the longterm impact of nutrition early in life on the development of conditions such as atherosclerosis (20), very little is known about how physical activity early in life could alter essential regulating mechanisms of body composition and impact muscle mass in adulthood. The purpose of this study was to test the hypotheses that increased physical activity in the newborn period would alter growth of skeletal muscle and circulating inflammatory cytokines during adulthood. We used a protocol of increased physical activity during early postnatal development in the rat. The neonatal rat is useful in this context in that 1) readily simple means can be used to increase physical activity and 2) the time interval for puberty and maturation is short. Consequently, the "adult" effects of early-life perturbations, if they occur, can be measured in a reasonable period of time.

It is known that gentle handling of rat pups during the immediate postnatal period has profound effects on the stress responses of these animals later in life. As adults, rats handled during the neonatal period secrete less corticosterone and have a faster corticosterone return to baseline after stress $(21,22)$.

Abbreviations: CON, control; DIO, diet-induced obesity; EX, exercised; HAND, handled; MG, medial gastrocnemius 
Moreover, Kruschinski et al. (23) recently reported that increased handling of rats as neonates attenuated airway inflammation in experimentally induced asthma in the adult animals. In the 1950s, Weininger (24) found that gently handled rats gained weight more rapidly and were significantly larger than the nonhandled animals by $21 \mathrm{~d}$ of life. Moreover, the handled animals were more physically active. Despite these intriguing studies, very little is currently known about the interaction of physical activity in early life, subsequent growth, and the regulation of inflammatory mediators. In this study, we tested our hypothesis using a novel protocol that enabled us to distinguish handling from increased physical activity in the neonatal period.

\section{METHODS}

All procedures were approved by the University of California Irvine Animal Care and Use Committee. Pregnant Sprague-Dawley dams were purchased (Charles River. Wilmington, MA). The litters were randomized, and the number of neonates normalized to eight (four males and four females) per dam using standard culling procedures on postpartum d 5 (25). Dams and litters were further randomized to three groups: control $(\mathrm{CON}, n=32)$, handled (HAND, $n=32$ ), and exercised (EX, $n=32$ ). The CON group consisted of litters that were transported to the laboratory each treatment day but not disturbed in any other way. Pups from the HAND group were held by researchers for the same durations as the exercise treatment (see below).

"Exercise" protocol. During the postpartum period, neonates in the EX treatment groups were removed from the dam and dispersed in a small (11 inch $\times 7$ inch) cage for 30 min once each day on postpartum d 5 through $d$ 10 and then $45 \mathrm{~min}$ per day for the next $5 \mathrm{~d}$ ( $10 \mathrm{~d}$ total ending on $\mathrm{d} 15)$. In pilot studies, these durations were found to be clearly submaximal. A small animal heating pad was placed under the treatment cage at one end creating a nesting area with slightly elevated temperature $\left(\sim 26^{\circ} \mathrm{C}\right)$. The activity protocol took advantage of the natural behavior of the rat pups to move to a warm spot in the cage and huddle together. During the exercise treatment period, the animals were repeatedly redispersed to promote crawling activity. Individual animals were tracked to achieve a uniform volume of crawling activity within and across groups.

Before each EX treatment, bedding from the home cage of the group was added to the treatment cage. In addition, research personnel handled the dam before touching the pups (HAND and EX). Rats from all groups were weaned at $22 \mathrm{~d}$ postpartum.

Tissue collection and analysis. Subgroups of rats were killed at 30 (equivalent to prepubertal humans) and 65 (equivalent to young adult humans) d postpartum (26). The rats were killed using Pentosol solution. Body mass was measured using a digital scale (Sartorius BP310P, Bradford, MA). After induction of deep anesthesia, before cessation of breathing, blood was collected from the left ventricle via the diaphragm using a heparinized syringe. The ventricles, soleus, plantaris, medial gastrocnemius (MG) muscles were dissected free of connective tissue, weighed, snap frozen, and stored at $-80^{\circ} \mathrm{C}$ for later analysis.

Muscle protein, myofibrillar protein, and DNA. Plantaris muscle samples were homogenized in sucrose buffer and myofibrillar proteins quantitatively extracted from a known volume of the total homogenate by a modification of the original procedure described by Solaro et al. (27). Protein concentrations were determined using the Bio-Rad Protein assay. Muscle total DNA concentration was determined using a fluorometric assay with DNA-specific fluorescent dye (28).

Plasma cytokine measurements blood sampling and analysis. Aliquoted plasma was stored at $-80^{\circ} \mathrm{C}$. Cytokine levels in plasma were measured using ELISA kits (R\&D Systems, Minneapolis, MN; Table 1).

Table 1. Plasma cytokine assay characteristics

\begin{tabular}{cccc}
\hline Cytokine & IL-1 $\beta$ & TNF $\alpha$ & IL-6 \\
\hline Intra-assay CV (\%) & $4.1-5.7$ & $2.1-5.1$ & $4.5-8.8$ \\
Interassay CV (\%) & $3.9-8.8$ & $8.8-9.7$ & $7.0-10.0$ \\
Sensitivity $(\mathrm{pg} / \mathrm{mL})$ & $\leq 5.0$ & $\leq 5.0$ & 22 \\
\hline
\end{tabular}

Statistical analysis. The values are reported as mean and SEM. Betweengroup analysis was conducted using a one-way ANOVA and Student posttest (PRISM-GraphPad, La Jolla, CA). For all statistical tests, the 0.05 level of confidence was accepted for statistical significance.

\section{RESULTS}

Growth effects of neonatal exercise. The growth rates of each group are presented in Table 2. No differences in body mass were found at $30 \mathrm{~d}$. The body mass of the EX rats was significantly lower than that of the CON and HAND groups in male adult ( $65 \mathrm{~d}$ ) rats (Table 3 ). At $65 \mathrm{~d}$, tibial length was not different between groups but had diverged by gender (male $37 \pm 0.3$ versus female $35 \pm 0.3 \mathrm{~mm} ; p<0.0001)$.

At the age of $65 \mathrm{~d}$, the relative mass ( $\mathrm{mg} / \mathrm{g}$ body weight) of leg muscles, such as the MG, was significantly greater in the male EX group (Table 4). Similar results were seen for soleus and plantaris muscle mass (data not shown).

The plantaris muscle was analyzed for both total and myofibrillar protein composition (Table 5). At the age of 30 and $65 \mathrm{~d}$, the total protein content of the plantaris muscle was greater in the male EX rats (8 and 11\%, respectively). Myofibrillar protein content was also significantly greater (15 and $20 \%$ ) in the male EX rats. At $65 \mathrm{~d}$, the myofibrillar protein content of female EX rat muscle was also $13 \%$ greater.

Prepubertal rats $(30 \mathrm{~d})$ that had been exposed to physical activity (EX) demonstrated significantly increased relative left ventricular mass (mg/g body) of $\sim 11 \%$ compared with CON (Table 6). This difference was apparent for both genders. At the age of $65 \mathrm{~d}$, relative left ventricle mass was significantly greater $(+12 \%)$ in EX males but not in females. No significant differences were found in DNA concentration at any time point.

Proinflammatory cytokines. At the age of $30 \mathrm{~d}$, the male EX rats had increased circulating levels of IL-6, whereas the levels of TNF $\alpha$ were decreased (Fig. 1). In $30 \mathrm{~d}$ females, circulating IL- $1 \beta$ concentration was increased in rats that had been handled (HAND) compared with the CON and EX groups.

In adult rats $(65 \mathrm{~d})$, both the HAND and EX groups had lower circulating levels of IL-6 that were similar in both genders (Fig. 2). In male adult rats of the EX group, circulating concentrations of both IL- $1 \beta$ and $\mathrm{TNF} \alpha$ were decreased (Fig. 2).

\section{DISCUSSION}

We found that a modest increase in physical activity in the neonatal period had significant effects on muscle mass and circulating inflammatory cytokines in adulthood. Early-life

Table 2. Body mass growth rate (assessed by exponential fit)

\begin{tabular}{|c|c|c|c|}
\hline & $\mathrm{CON}$ & HAND & EX \\
\hline \multicolumn{4}{|l|}{ Female } \\
\hline$k$ & $0.0363 \pm 0.0015$ & $0.0374 \pm 0.0014$ & $0.0361 \pm 0.0012$ \\
\hline Fit $\left(r^{2}\right)$ & 0.96 & 0.96 & 0.97 \\
\hline \multicolumn{4}{|l|}{ Male } \\
\hline$k$ & $0.0446 \pm 0.0017$ & $0.0460 \pm 0.0012$ & $0.0434 \pm 0.0016$ \\
\hline Fit $\left(r^{2}\right)$ & 0.98 & 0.99 & 0.97 \\
\hline
\end{tabular}

$k=$ rate constant. 
Table 3. Effects of $10 d$ of neonatal exercise on body mass

\begin{tabular}{lccc}
\hline Body Mass & CON & HAND & EX \\
\hline Male 30 d & $95 \pm 3$ & $95 \pm 2$ & $101 \pm 1$ \\
Female 30 d & $87 \pm 3$ & $89 \pm 1$ & $93 \pm 1$ \\
Male 65 d & $375 \pm 10$ & $369 \pm 5$ & $343 \pm 10^{* \dagger}$ \\
Female 65 d & $226 \pm 5$ & $236 \pm 9$ & $237 \pm 4$ \\
\hline
\end{tabular}

$n=8$.

$* p<0.05$ vs CON.

$\dagger p<0.05$ vs HAND.

Table 4. Effects of $10 \mathrm{~d}$ of neonatal exercise on medial gastrocnemius muscle mass

\begin{tabular}{lrrr}
\hline $\begin{array}{c}\text { Medial Gastrocnemius } \\
\text { (mg/g body) }\end{array}$ & \multicolumn{1}{c}{ CON } & \multicolumn{1}{c}{ HAND } & \multicolumn{1}{c}{ EX } \\
\hline Male $30 \mathrm{~d}$ & $1.9 \pm 0.03$ & $1.9 \pm 0.03$ & $1.9 \pm 0.06$ \\
Female $30 \mathrm{~d}$ & $2.0 \pm 0.03$ & $1.9 \pm 0.02$ & $2.0 \pm 0.03$ \\
Male $65 \mathrm{~d}$ & $2.40 \pm 0.05$ & $2.34 \pm 0.10$ & $2.72 \pm 0.12^{* \dagger}$ \\
Female $65 \mathrm{~d}$ & $2.64 \pm 0.02$ & $2.52 \pm 0.06$ & $2.56 \pm 0.06$ \\
\hline$n=8$. & & & \\
$* p<0.05$ vs CON. & & & \\
$\dagger p<0.05$ vs HAND. & & &
\end{tabular}

exercise, but not handling alone, led to significant increases in skeletal muscle mass and myofibrillar protein in adulthood. The muscle effects occurred in both males and females but were more pronounced in the males. The increase in muscle mass and protein was not accompanied by increased body weight, indeed, the male rats that had exercised as neonates weighed significantly less as adults (Table 3 ). Bone length was not affected by the early-in-life exercise, suggesting that the lower body weights did not result from a global catabolic effect of early exercise. Left ventricular mass was greater in adult rats that had exercised as neonates. It is important to note that all programmed exercise ceased at postpartum d 15 . Therefore, the data from the prepubertal and adult animals represent time points either 15 or $50 \mathrm{~d}$ after the last programmed exercise. This suggests that between-group differences represent relatively long-lived effects.

Although statistically significant, the magnitude of the effects on muscle mass and myofibrillar protein seem to be modest. Changes of this magnitude in the newborn period are deceptively small relative to potential long-term consequences, $(18,29,30)$ perhaps due to "reprogramming." For example, Stettler et al. (31) observed that for every $100 \mathrm{~g}$ increase in weight gain during the first week of infancy, there was a $28 \%$ increase in the risk of adult obesity in American formula-fed subjects. We speculate that the increase in muscle myofibrillar protein that we observed in the adult rats that had exercised as neonates reflects a broad, heretofore undiscovered set of biological mechanisms that likely affect more than just muscle size.

A unique feature of this study was the specific measurement of myofibrillar protein content in addition to the gross mass of specific muscle groups. The measurement of muscle mass can be confounded by a number of factors including intramuscular fat, which can be influenced by specific genetic factors during growth (32), and connective tissue, which can be affected by physical activity (33). Myofibrillar protein content accurately reflects the pool of functional proteins that account for the ability of muscles to perform work (34). Although relatively poorly studied in the neonatal period, changes in myofibrillar elements can occur leading to improved function, without concomitant increases in overall muscle size (35). Our finding of increased myofibrillar protein content in adult rats indicates that a profound, developmentally sensitive and functionally consequential reprogramming event had occurred earlier in life as a result of the neonatal exercise.

Increased cardiac work (pressure load) is a well-established cause of increased heart muscle. Far less is known about the impact of physical activity on cardiac dimensions in children, and reports are contradictory. For example, although increased cardiac work secondary to obesity can alter cardiac dimensions in children (36), Dencker et al. (37) found no association between physical activity in children and cardiac dimensions. Our study is the first to show an effect of neonatal exercise on subsequent cardiac size and an effect that was observed at $30 \mathrm{~d}$ in both males and females and at $60 \mathrm{~d}$ in males. The physiological and functional impact of this adaptation is as yet unknown. However, it is assumed that increased oxygen demand resulted in increased cardiac output, e.g. flow work, rather than pressure work, leading to functional hypertrophy.

These data add to a small but growing number of studies suggesting that early-life physical activity might benefit body composition throughout the lifespan. For example, Levin (38) has selectively bred rats to manifest a diet-induced obesity (DIO) phenotype. These investigators found that only $3 \mathrm{wk}$ of exercise early in life was sufficient to prevent DIO rats from becoming obese for up to $10 \mathrm{wk}$ once the exercise was terminated. Similar effects were not observed in adult DIO rats. Finally, in marked contrast to early-in-life exercise, early-in-life caloric restriction led to DIO animals that were more obese as adults once allowed to eat ad libitum.

Gender dimorphism in physiological and muscle responses to exercise and training are well-described (39), and we found gender differences in the adult response to neonatal exercise. Interestingly, others have reported that the body composition of female rats is much less sensitive to perturbations, such as running exercise or cardiac cachexia, than that of males $(40,41)$. Colom et al. (42) recently demonstrated that gastrocnemius muscle in female rats had higher mitochondrial DNA and protein contents, in addition to oxidative and phosphorylative enzymatic machinery, which could explain the higher facility of females to adapt to altered metabolic energy situations. Perhaps, if this gender-related metabolic advantage exists in the skeletal muscle of the neonatal rat, then the perturbation imposed by early-life exercise was mitigated in the females thereby muting any long-term adaptive or reprogramming processes. In addition, we designed the experiment to find changes in muscle properties in the late to postpubertal maturational stages. It remains possible that some combination of the pubertal sex steroids, estradiols and testosterone, that are known to influence skeletal muscle differently (43) with the, as yet, undefined signal from neonatal exercise led to an attenuated effect on muscle size in the adult female rats.

A key finding of this study was the effect of neonatal exercise on levels of circulating inflammatory mediators later in life. In addition to their catabolic properties, stress and 
Table 5. Effects of neonatal $10 \mathrm{~d}$ of exercise on muscle protein

\begin{tabular}{|c|c|c|c|c|c|c|}
\hline & \multicolumn{3}{|c|}{ Total Protein (mg) } & \multicolumn{3}{|c|}{ Myofibrillar Protein (mg) } \\
\hline & $\mathrm{CON}$ & HAND & EX & $\mathrm{CON}$ & HAND & EX \\
\hline Male $30 \mathrm{~d}$ & $14.9 \pm 0.9$ & $14.7 \pm 0.5$ & $16.2 \pm 0.6^{*}$ & $7.6 \pm 0.4$ & $7.5 \pm 0.2$ & $8.7 \pm 0.3^{* \dagger}$ \\
\hline Female $30 \mathrm{~d}$ & $13.3 \pm 0.8$ & $13.7 \pm 0.3$ & $14.7 \pm 0.7$ & $7.9 \pm 0.3$ & $7.7 \pm 0.2$ & $7.7 \pm 0.5$ \\
\hline Male $65 \mathrm{~d}$ & $82 \pm 3$ & $79 \pm 2$ & $91 \pm 2 * \dagger$ & $43 \pm 3$ & $44 \pm 1$ & $51 \pm 2^{* \dagger}$ \\
\hline Female $65 \mathrm{~d}$ & $57 \pm 2$ & $58 \pm 1$ & $61 \pm 2$ & $30 \pm 1$ & $31 \pm 1$ & $34 \pm 1 * \dagger$ \\
\hline
\end{tabular}

$n=8$.

$* p<0.05 v s$ HAND

$\dagger p<0.05$ vs CON.

Table 6. Effects of $10 \mathrm{~d}$ of neonatal exercise on left ventricle muscle mass

\begin{tabular}{lccc}
\hline MG (mg/g body) & CON & HAND & EX \\
\hline Male 30 d & $3.9 \pm 0.1$ & $3.7 \pm 0.1$ & $4.2 \pm 0.1^{* \dagger}$ \\
Female 30 d & $3.9 \pm 0.1$ & $3.9 \pm 0.1$ & $4.5 \pm 0.1^{* \dagger}$ \\
Male 65 d & $2.6 \pm 0.1$ & $2.7 \pm 0.1$ & $2.9 \pm 0.1^{* \dagger}$ \\
Female 65 d & $2.9 \pm 0.0$ & $3.0 \pm 0.1$ & $3.1 \pm 0.0$ \\
\hline
\end{tabular}

$n=8$.

$* p<0.05$ vs. CON.

$\dagger p<0.05$ vs. HAND.
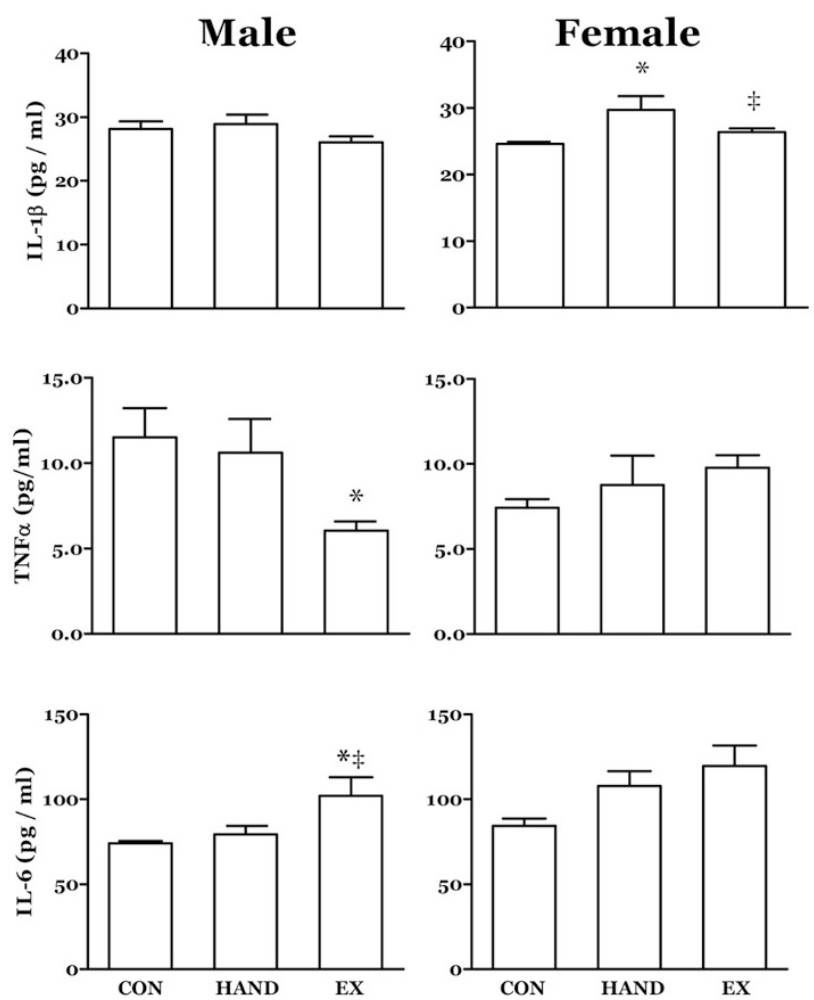

Figure 1. The effects of prior neonatal activity on selected circulating cytokines at postpartum d 30. Rat neonates experienced increased physical activity (EX), handling (HAND), or no treatment (CON) from postpartum d 5 through $\mathrm{d} 15$. A subgroup was sampled at $\mathrm{d} 30$. The neonatal activity treatment resulted in lower circulating levels of TNF $\alpha$ and higher IL-6 in 30-d males. Plasma levels of IL- $1 \beta$ were elevated in HAND rats relative to CON and EX. $n=8 ; *, p<0.05 v s$. CON; $\ddagger p<0.05 v s$. HAND.

inflammatory mediators such as IL-6, TNF $\alpha$, and IL- $1 \beta$ are all involved in atherosclerosis and increased risk for cardiovascular disease (44-46). Not surprisingly, most research focused on neonatal programming during critical periods of growth are centered on the pediatric origins of adult disease and target abnormal early-life events [e.g. small for GA,
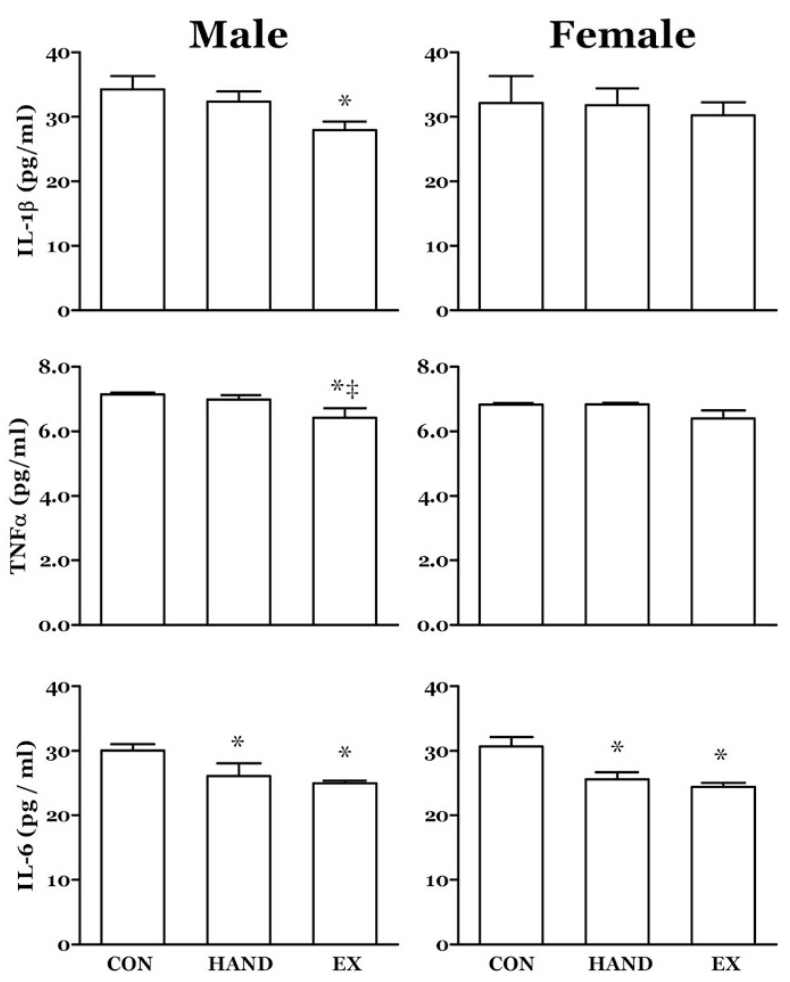

Figure 2. The effects of prior neonatal activity on selected circulating cytokines at postpartum d 65. Rat neonates experienced increased physical activity (EX), handling (HAND), or no treatment (CON) from postpartum d 5 through $d$ 15. A subgroup was sampled at $d$ 65. In males, the neonatal activity treatment resulted in lower circulating levels of IL-6, TNF $\alpha$, and IL- $1 \beta$ at the age of $60 \mathrm{~d}$. Plasma levels of IL- 6 were also lower in $65 \mathrm{~d}$ EX females. Both male and female HAND rats demonstrated IL-6 levels that were lower than CON. $n=8 ; *, p<0.05$ vs. CON; $\neq, p<0.05$ vs. HAND.

prematurely born infants being predisposed to adult obesity and cardiovascular disease (47-49)]. Ours is one of the first studies to examine perturbations during critical developmental periods in otherwise healthy newborns. First, we found that both handling and exercise during the neonatal period led to decreased circulating levels of IL-6 in both male and female 
adult rats. Although we did not record the impact of either handling or exercise during the neonatal period on subsequent patterns of physical activity, the data from Weininger (24) cited early suggested that handling in and of itself leads to increased physical activity which, perhaps, was a common stimulus for the subsequent changes in circulating cytokines observed later in life.

We also found evidence of gender dimorphism in the effect of neonatal interventions on inflammatory cytokine profiles later in life. In males, but not in females, the early exercise intervention influenced TNF $\alpha$ and IL-1 $\beta$ in the adult animals. Gender dimorphism in inflammatory mediator responses to a variety of perturbations is now well established $(50,51)$, and most authors attribute these differences, in part, to the varied effects of the sex steroids on immune responsive cells. However, the mechanisms responsible for the gender dimorphism in the late-effect cytokine profiles in our study remain elusive.

In general, the regulation of circulating levels of inflammatory mediators such as IL-6 has undergone substantial rethinking in recent years. For example, the discovery that IL-6 is produced by muscle tissue and not solely immune cells and that exercising muscle is responsible for the increase in IL-6 observed with exercise $(52,53)$ have led to the novel idea that muscle itself plays a role in endocrine and inflammatory regulation. We did find significant changes in myofibrillar protein in adult muscles consequent to exercise early in life. This leads to the intriguing hypothesis that skeletal muscle itself plays a more active role in the regulation of circulating inflammatory cytokines than previously imagined.

There are a number of potential limitations to this study. Differences in maternal care could contribute to lasting effects seen in adult animals. To minimize this effect, each group in this study consisted of litters reared by four different dams which would be expected to randomly distribute any differences in maternal behaviors. Analysis of growth rates by litter did not indicate any maternal bias (data not shown).

There are also reports of gender-specific preferences in maternal care (e.g. Ref. 54). However, this is not a universal finding (55). In murine species, effects of gender differences in care seem to be primarily confined to later behavioral differences (e.g. Ref. 56) but not necessarily physiological development (57). In this study, the gender-specific growth rates through weaning were very similar, indicating that this was not a confounding factor (data not shown). The estrous phase of the female rats was not controlled and could have affected the plasma cytokine results.

In summary, the unique finding of this experiment was that a relatively brief intervention that modestly increased physical activity in a critical period of neonatal development in the rat led to changes in skeletal muscle and heart mass and circulating inflammatory cytokine profiles in the adult animals. The changes were influenced by gender. The observed increases in muscle mass and myofibrillar protein were not accompanied by increases in body weight, findings consistent with previous studies of exercise intervention in rats indicating that earlyin-life exercise mitigates adult onset obesity. In addition, through mechanisms that are still unclear, the early-in-life exercise was associated with a reduction in inflammatory cytokines that are known to antagonize skeletal muscle growth and contribute to the development of cardiovascular disease. These studies provide experimental models to elucidate novel mechanisms of long-term effects of exercise in early, critical periods of growth. Such research could complement clinical studies targeting the role of exercise in newborns $(58,59)$ and children as adjunctive or preventive therapy both in health (e.g. to prevent obesity) or to attenuate the deleterious effects of chronic inflammatory diseases of childhood.

\section{REFERENCES}

1. Bechtold S, Alberer M, Arenz T, Putzker S, Filipiak-Pittroff B, Schwarz HP, Koletzko S 2010 Reduced muscle mass and bone size in pediatric patients with inflammatory bowel disease. Inflamm Bowel Dis 16:216-225

2. Bechtold S, Dalla PR, Schwarz HP, Simon D 2009 Effects of growth hormone treatment in juvenile idiopathic arthritis: bone and body composition. Horm Res 72:60-64

3. Moser C, Tirakitsoontorn P, Nussbaum E, Newcomb R, Cooper DM 2000 Muscle size and cardiorespiratory response to exercise in cystic fibrosis. Am J Respir Crit Care Med 162:1823-1827

4. Ralt D 2006 The muscle-fat duel or why obese children are taller? BMC Pediatr $6: 33$

5. Vahlkvist S, Pedersen S 2009 Fitness, daily activity and body composition in children with newly diagnosed, untreated asthma. Allergy 64:1649-1655

6. Adams GR 2002 Autocrine/paracrine IGF-I and skeletal muscle adaptation. J Appl Physiol 93:1159-1167

7. Nystrom G, Pruznak A, Huber D, Frost RA, Lang CH 2009 Local insulin-like growth factor I prevents sepsis-induced muscle atrophy. Metabolism 58:787-797

8. Gleeson M 2007 Immune function in sport and exercise. J Appl Physiol 103:693699

9. Gleeson M, Bishop NC 2005 The T cell and NK cell immune response to exercise. Ann Transplant 10:43-48

10. Ahmad I, Zaldivar F, Iwanaga K, Koeppel R, Grochow D, Nemet D, Waffarn F, Eliakim A, Leu SY, Cooper DM 2007 Inflammatory and growth mediators in growing preterm infants. J Pediatr Endocrinol Metab 20:387-396

11. Grounds MD 2002 Reasons for the degeneration of ageing skeletal muscle: a central role for IGF-1 signalling. Biogerontology 3:19-24

12. Haddad F, Zaldivar F, Cooper DM, Adams GR 2005 IL-6-induced skeletal muscle atrophy. J Appl Physiol 98:911-917

13. Pass C, MacRae VE, Ahmed SF, Farquharson C 2009 Inflammatory cytokines and the GH/IGF-I axis: novel actions on bone growth. Cell Biochem Funct 27:119-127

14. Yang G, Badeanlou L, Bielawski J, Roberts AJ, Hannun YA, Samad F 2009 Central role of ceramide biosynthesis in body weight regulation, energy metabolism, and the metabolic syndrome. Am J Physiol Endocrinol Metab 297:E211-E224

15. Barker DJ, Eriksson JG, Forsen T, Osmond C 2002 Fetal origins of adult disease: strength of effects and biological basis. Int J Epidemiol 31:1235-1239

16. Cameron N, Demerath EW 2002 Critical periods in human growth and their relationship to diseases of aging. Am J Phys Anthropol 119(suppl 35):159-184

17. Gicquel C, El-Osta A, Le BY 2008 Epigenetic regulation and fetal programming. Best Pract Res Clin Endocrinol Metab 22:1-16

18. McMillen IC, Rattanatray L, Duffield JA, Morrison JL, MacLaughlin SM, Gentili S, Muhlhausler BS 2009 Early origins of later obesity: pathways and mechanisms. Adv Exp Med Biol 646:71-81

19. Nesterenko TH, Aly H 2009 Fetal and neonatal programming: evidence and clinical implications. Am J Perinatol 26:191-198

20. Singhal A 2006 Early nutrition and long-term cardiovascular health. Nutr Rev 64:S44-S49

21. Levine S 1957 Infantile experience and resistance to physiological stress. Science 126:405

22. Meaney MJ, Mitchell JB, Aitken DH, Bodnoff SR, Iny LJ, Sarrieau A 1991 The effects of neonatal handling on the development of the adrenocortical response to stress: implications for neuropathology and cognitive deficits in later life. Psychoneuroendocrinology 16:85-103

23. Kruschinski C, Skripuletz T, Bedoui S, Raber K, Straub RH, Hoffmann T, Grote K, Jacobs R, Stephan M, Pabst R, von Hörsten S 2008 Postnatal life events affect the severity of asthmatic airway inflammation in the adult rat. J Immunol 180:39193925

24. Weininger O 1956 The effects of early experience on behavior and growth characteristics. J Comp Physiol Psychol 49:1-9

25. Agnish ND, Keller KA 1997 Rationale for culling of rodent litters. Fundam Appl Toxicol 38:2-6

26. Evans AM 1986 Age at puberty and first litter size in early and late paired rats. Biol Reprod 34:322-326

27. Solaro RJ, Pang DC, Briggs FN 1971 Purification of cardiac myofibrils with Triton X-100. Biochim Biophys Acta 245:259-262

28. Labarca C, Paigen K 1980 DNA assay procedure. Anal Biochem 102:344-352

29. Morris MJ, Velkoska E, Cole TJ 2005 Central and peripheral contributions to obesity-associated hypertension: impact of early overnourishment. Exp Physiol 90:697-702 
30. Ong KK, Emmett PM, Noble S, Ness A, Dunger DB 2006 Dietary energy intake at the age of 4 months predicts postnatal weight gain and childhood body mass index. Pediatrics 117:e503-e508

31. Stettler N, Stallings VA, Troxel AB, Zhao J, Schinnar R, Nelson SE, Ziegler EE, Strom BL 2005 Weight gain in the first week of life and overweight in adulthood: a cohort study of European American subjects fed infant formula. Circulation 111:1897-1903

32. Fan B, Du ZQ, Rothschild MF 2009 Fat mass and obesity-associated gene is associated with intramuscular fat content and growth rate in the pig. Anim Biotechnol 20:58-70

33. Willems ME, Miller GR, Stauber FD 2010 Stauber WT Effects of repeated lengthening contractions on skeletal muscle adaptations in female rats. J Physiol Sci 60:143-150

34. Glover EI, Phillips SM, Oates BR, Tang JE, Tarnopolsky MA, Selby A, Smith K, Rennie MJ 2008 Immobilization induces anabolic resistance in human myofibrillar protein synthesis with low and high dose amino acid infusion. J Physiol 586:60496061

35. Gokhin DS, Ward SR, Bremner SN, Lieber RL 2008 Quantitative analysis of neonatal skeletal muscle functional improvement in the mouse. J Exp Biol 211:837843

36. Peralta-Huertas J, Livingstone K, Banach A, Klentrou P, O'Leary D 2008 Differences in left ventricular mass between overweight and normal-weight preadolescent children. Appl Physiol Nutr Metab 33:1172-1180

37. Dencker M, Thorsson O, Karlsson MK, Linden C, Wollmer P, Andersen LB 2009 Objectively measured daily physical activity related to cardiac size in young children. Scand J Med Sci Sports 19:664-668

38. Levin BE 2008 Epigenetic influences on food intake and physical activity level: review of animal studies. Obesity (Silver Spring) 16:S51-S54

39. Galassetti P, Neill AR, Tate D, Ertl AC, Wasserman DH, Davis SN 2001 Sexual dimorphism in counterregulatory responses to hypoglycemia after antecedent exercise. J Clin Endocrinol Metab 86:3516-3524

40. Cortright RN, Chandler MP, Lemon PW, DiCarlo SE 1997 Daily exercise reduces fat, protein and body mass in male but not female rats. Physiol Behav 62:105-111

41. Palus S, Akashi Y, vonHaehling S, Anker SD, Springer J 2009 Influence of age and sex on disease development in a novel animal model of cardiac cachexia. Int J Cardiol 133:388-393

42. Colom B, Alcolea MP, Valle A, Oliver J, Roca P, Garcia-Palmer FJ 2007 Skeletal muscle of female rats exhibit higher mitochondrial mass and oxidativephosphorylative capacities than males. Cell Physiol Biochem 19:205-212

43. Paroo Z, Dipchand ES, Noble EG 2002 Estrogen attenuates postexercise HSP70 expression in skeletal muscle. Am J Physiol Cell Physiol 282:C245-C251
44. Grundtman C, Hollan I, Forre OT, Saatvedt K, Mikkelsen K, Lundberg IE 2010 Cardiovascular disease in patients with inflammatory rheumatic disease is associated with up-regulation of markers of inflammation in cardiac microvessels and cardiomyocytes. Arthritis Rheum 62:667-673

45. Gustafson B 2010 Adipose tissue, inflammation and atherosclerosis. J Atheroscler Thromb 17:332-341

46. Zee RY, Glynn RJ, Cheng S, Steiner L, Rose L, Ridker PM 2009 An evaluation of candidate genes of inflammation and thrombosis in relation to the risk of venous thromboembolism: The Women's Genome Health Study. Circ Cardiovasc Genet 2:57-62

47. Metges CC 2009 Early nutrition and later obesity: animal models provide insights into mechanisms. Adv Exp Med Biol 646:105-112

48. Singhal A 2009 The early origins of atherosclerosis. Adv Exp Med Biol 646:51-58

49. Srinivasan M, Patel MS 2008 Metabolic programming in the immediate postnatal period. Trends Endocrinol Metab 19:146-152

50. Diodato MD, Knoferl MW, Schwacha MG, Bland KI, Chaudry IH 2001 Gender differences in the inflammatory response and survival following haemorrhage and subsequent sepsis. Cytokine 14:162-169

51. Edwards KM, Burns VE, Ring C, Carroll D 2006 Individual differences in the interleukin-6 response to maximal and submaximal exercise tasks. J Sports Sci 24:855-862

52. Febbraio MA, Pedersen BK 2005 Contraction-induced myokine production and release. Exerc Sport Sci Rev 33:114-119

53. Jonsdottir IH, Schjerling P, Ostrowski K, Asp S, Richter EA, Pedersen BK 2000 Muscle contractions induce interleukin-6 mRNA production in rat skeletal muscles. J Physiol 528:157-163

54. Moore CL, Morelli GA 1979 Mother rats interact differently with male and female offspring. J Comp Physiol Psychol 93:677-684

55. Champagne FA, Francis DD, Mar A, Meaney MJ 2003 Variations in maternal care in the rat as a mediating influence for the effects of environment on development Physiol Behav 79:359-371

56. Moore CL, Power KL 1992 Variation in maternal care and individual differences in play, exploration, and grooming of juvenile Norway rat offspring. Dev Psychobiol 25:165-182

57. Alleva E, Caprioli A, Laviola G 1989 Litter gender composition affects maternal behavior of the primiparous mouse dam. J Comp Psychol 103:83-87

58. Eliakim A, Nemet D 2005 Osteopenia of prematurity-the role of exercise in prevention and treatment. Pediatr Endocrinol Rev 2:675-682

59. Moyer-Mileur LJ, Brunstetter V, McNaught TP, Gill G, Chan GM 2000 Daily physical activity program increases bone mineralization and growth in preterm very low birth weight infants. Pediatrics 106:1088-1092 